\title{
Advanced ventilatory support and mortality in hospitalized patients with COVID-19 caused by Gamma (P.1) variant of concern compared to other lineages: cohort study at a reference center in Brazil
}

\author{
Alexandre Prehn Zavascki ( $\nabla$ azavascki@hcpa.edu.br) \\ Federal University of Rio Grande do Sul: Universidade Federal do Rio Grande do Sul \\ https://orcid.org/0000-0001-5331-4837 \\ Tarsila Vieceli \\ Hospital de Clinicas de Porto Alegre \\ Priscila Lamb Wink \\ Hospital de Clinicas de Porto Alegre
}

Fabiana Caroline Zempulski Volpato

Hospital de Clinicas de Porto Alegre

Francielle Liz Monteiro

Hospital de Clinicas de Porto Alegre

Julia Biz Willig

Hospital de Clinicas de Porto Alegre

Charles Francisco Ferreira

Hospital de Clinicas de Porto Alegre

Beatriz Arns

Hospital de Clinicas de Porto Alegre

Guilherme Oliveira Magalhães

Hospital de Clinicas de Porto Alegre

Matheus Niches Costa

Hospital de Clinicas de Porto Alegre

Andreza Francisco Martins

Hospital de Clinicas de Porto Alegre

Afonso Luís Barth

Hospital de Clinicas de Porto Alegre

Research Article 
Keywords: Coronavirus Disease 19, Severe Acute Respiratory Syndrome Coronavirus 2, Variant of Concern; Cohort Study, Non-invasive ventilation, Invasive ventilation, Mortality

Posted Date: September 17th, 2021

DOI: https://doi.org/10.21203/rs.3.rs-910467/v1

License: (c) (1) This work is licensed under a Creative Commons Attribution 4.0 International License. Read Full License 


\section{Abstract \\ Background}

The Severe Acute Respiratory Syndrome Coronavirus 2 (SARS-CoV-2) variant of concern (VOC) Gamma (P.1) has increased transmissibility and resulted in elevated hospitalization, intensive care unit occupancy and mortality rates in Brazil. It is not known whether this VOC is also associated with more severe clinical course of disease.

\section{Methods}

This was a retrospective cohort study with non-elderly patients hospitalized for COVID-19 from June to December/2020 (first period) and February to May/2021 (second period) at a reference hospital in Brazil. Two cohorts were performed: the main cohort, composed by patients with SARS-CoV-2 lineages confirmed by whole genome sequencing; and the sensitivity cohort, composed by all eligible patients admitted before and after the emergence of Gamma. The primary outcome was the incidence rate of need of advanced ventilatory support.

\section{Results}

In the main cohort a total of 86 (43 Gamma and 43 non-Gamma) patients were included. Baseline characteristics were similar, except that Gamma patients had lower median Charlson's comorbidity score. The crude and adjusted incidence rates of advanced respiratory support (adjusted Hazard Ratio [aHR], 1.78; 95\% Confidence Interval [Cl], 1.05-3.03), invasive respiratory support (aHR, 2.64; 95\% Cl, 1.34-5.19) and 28-day mortality from onset of symptoms (aHR, 4.73; 95\% Cl, 1.15-19.41) and adjusted 28-day mortality from hospital admission (aHR, 3.72; $95 \% \mathrm{Cl}, 1.19-11.65)$ were significantly higher in patients infected by Gamma. These patients had significantly lower days alive and free of supplemental oxygen support. The sensitivity cohort included 433 patients: 259 from the first and 174 from the second period (before and after the emergence of Gamma, respectively). Baseline characteristics were similar, except for a higher incidence of severe distress respiratory syndrome in patients from second group at admission. Patients from the second period had significantly higher incidence rates of advanced respiratory support (aHR, 2.04; 95\% Cl, 1.60-2.59), invasive ventilatory support (aHR, 2.72; 95\% Cl, 2.05-3.62), and 28-day mortality from the onset of symptoms (aHR, 2.62; $95 \% \mathrm{Cl}, 1.46-4.72)$.

\section{Conclusions}

Our study suggests that in non-elderly hospitalized patients, COVID-19 caused by Gamma VOC may present a more severe clinical course, with increased need of advanced respiratory support and higher 28day mortality. 


\section{Introduction}

Since September 2020 four Severe Acute Respiratory Syndrome Coronavirus 2 (SARS-CoV-2) variants of concern (VOC) have emerged in different parts of the word, further complicating the efforts to control the Coronavirus Disease 19 (COVID-19) pandemic [1]. Alpha (B.1.1.7), Gamma (P.1) and Delta (B.1.617.2) are variants of concern (VOCs) associated with increased transmissibility [1-4] and are implicated with COVID-19 surges followed by increased hospitalizations, intensive care unit (ICU) overload and higher death rates [1-4]. Despite these effects, it is not clear whether these VOCs are associated with a more severe course of COVID-19.

Some studies performed at population-level suggest that Alpha [5-9] infections are associated with higher hospitalization rates when compared to non-VOC lineages. However, the absence of a more detailed analysis of the clinical course at a patient level may prevent definitive conclusions on the clinical course of COVID-19 caused by different variants [10]. Two studies evaluating covariates at an individual level found distinct results $[11,12]$. An increased risk of death of the Alpha variant was not found in hospitalized patients [11], while in a community-based study, a higher risk of critical care admission and 28-day mortality was observed [12]. Nevertheless, these studies have neither evaluated the ventilatory support progression during hospitalization nor other variables that might indicate a more frequent or earlier need of more critical life support.

The Gamma variant has caused a dramatic surge of COVID-19 cases, hospitalizations, ICU demand and deaths in the Amazon region, Brazil [3, 13]. Gamma lineage has further spread to other Brazilian regions, determining huge hospital system overload, and further spread to other South and North American countries [1, 14-16] and Europe [17]. Despite this large impact over hospitalizations and mortality rates, so far, there is no study addressing whether this VOC is associated with more severe disease. In this study, we investigate the requirement of ventilatory support and mortality rates in non-elderly adult patients hospitalized due to COVID-19 caused by Gamma and non-Gamma SARS-CoV-2 lineages.

\section{Methods}

\section{Study design, setting and participants}

This is a retrospective cohort study carried out at Hospital de Clínicas de Porto Alegre (HCPA), a tertiarycare, COVID-19 reference hospital, located at the city of Porto Alegre (1,488,000 in-habitants), the capital of Rio Grande do Sul State, Brazil.

The study population was composed of patients $\geq 18$ and $\leq 65$ years admitted at the emergency department of HCPA in two periods, classified according to the first detection of Gamma variant in the State: first period, before the detection of Gamma (1st June to 31st December/2020) and second period, after the detection of Gamma (1 st February to 31st May/2021). Since the first detection of Gamma in our State was in January/2021 [14], it was considered a month of transition from the predominance of other lineages to predominance of Gamma, and patients admitted in this month were not considered for 
inclusion. Only patients whose real-time reverse transcriptase polymerase chain reaction (RT-qPCR) cycle threshold (Ct) value for both SARS-CoV-2 nucleocapsid protein N1 and N2 gene targets were $<26$, allowing a higher quality whole genome sequencing (WGS), were considered for the study. Patients were excluded if they were transferred from another hospital or if they were admitted because of non-COVID-19 related diseases and had a positive screening test.

Two cohorts were designed for eligible patients. The main cohort was composed by sample of randomly selected individuals who had their RT-qPCR samples sequenced. In this cohort, patients were further excluded if WGS generated a low-quality sequence. The sensitivity cohort was composed by all eligible patients: those from the second period were considered as having Gamma infection and those from the first period were considered non-Gamma infections.

\section{Ethical aspects}

This study is part of a research project on the epidemiology of SARS-CoV-2. It has been approved by the Institutional Ethics Committee (Project no. 2020 - 0163), which waived informed consent. A specific amendment to this study was submitted and approved by this committee. This study was registered at ClinicalTrials.gov under the number NCT04928469 (https://clinicaltrials.gov/ct2/show/NCT04928469).

\section{Baseline characteristics}

The following variables were assessed at hospital admission: age; sex; body mass index; Charlson's Comorbidity Score and specific comorbidities; National Early Warning Score 2 (only in the main cohort); number of days from onset of symptoms to hospital admission; 6-point ordinal scale classification at admission; partial pressure of arterial oxygen/ fraction of inspired oxygen (PaO2/FiO2) ratio; and laboratory values.

\section{Outcomes}

The primary outcome was incidence of need for advanced respiratory support within 28 days from the onset of symptoms. Advanced respiratory support was defined as the requirement of supplementary oxygen by non-invasive ventilation, high-flow nasal cannula, mechanical ventilation, or extracorporeal membrane oxygenation. The main prespecified secondary outcomes, which were evaluated in both main and sensitivity cohorts, were incidence of need of invasive ventilatory support (requirement of mechanical ventilation or extracorporeal membrane oxygenation) from the onset of symptoms; 28-day mortality from onset of symptoms and from hospital admission; Other secondary outcomes, evaluated only in the main cohort, were progression in an ordinal clinical scale of COVID-19 severity during the first 28 days and $\mathrm{PaO} 2 / \mathrm{FiO} 2$ ratio during hospitalization. Definitions and other secondary outcomes are described in the Additional file 1.

\section{Whole Genome Sequencing}

The procedure is described in the Additional file 1.

\section{Statistical Analysis}


The sample size was estimated in 86 patients (43 Gamma and 43 non-Gamma patients) as detailed in Additional file 1.

Bivariate analysis of Gamma and non-Gamma-infected patients baseline characteristics was performed using Student's T or Mann-Whitney tests for continuous variables, and chi-square test or Fisher's exact test for categorical variables.

Kaplan-Meier estimates for the need for advanced respiratory support were calculated, and the difference between groups was compared using the log-rank test.

Cox proportional hazard models were performed to evaluate the effect of Gamma infection on the need of advanced respiratory support, need of invasive ventilatory support and 28-day mortality from onset of symptoms including the following variables age, sex, body mass index and Charlson's score. Other baseline variables were not considered in this model since they are supposed to represent at some degree the severity of illness and, therefore, are not confounding variables for this outcome. For 28-day mortality from hospitalization, other variables at admission were considered as detailed in Additional file 1.

Other secondary outcomes were assessed as described in the statistical analysis plan, which can be found at https://clinicaltrials.gov/ct2/show/NCT04928469, and detailed in the Additional file 1.

The database was double entered, revised and validated in the SPSS program (version 18.0). All tests were two-tailed and a $P$ value $\leq 0.05$ was considered statistically significant.

\section{Results}

\section{Characteristics of patients}

A total of 2434 patients had a positive result of SARS-CoV-2 RT-qPCR collected at the emergency department. Exclusions occur as displayed in the study flowchart (Fig. 1). A total of 433 patients eligible for the study and composed the sensitivity cohort: 174 (40.2\%) patients from the first period and 259 (59.8\%) from the second period. Ninety-seven randomly selected patients had their samples sequenced, 8 were excluded because the WGS presented low quality (average coverage $<350$ ), and 1 Gamma patient recovered in the first period and 2 non-Gamma from the second period were excluded because the first 86 patients planned to compose the main cohort had already been included (Fig. 1).

Four of 43 samples from the Gamma group were Gamma sub-lineages (2 P.1.1 and 2 P.1.2). Most lineages included in the non-Gamma group were B.1.1.28 (15, 34.9\%) and B.1.1.161 (10, 23.3\%) (Additional file 1: STable1); other non-Gamma lineages are presented in Additional file 1: STable 2.

\section{Baseline characteristics}

Gamma patients had a lower Charlson's comorbidity score and lower platelet count at admission (Table 1). Other characteristics at admission were similar between groups (Table 1). A total of 41 (95.3\%) 
and 39 (90.7\%) Gamma and non-Gamma-infected patients ( $P=0.67)$, respectively, received corticosteroids as a part of COVID-19 management during hospitalization. No other therapy such as remdesivir or tocilizumab was administered. 
Table 1

Baseline characteristics of patients.

\begin{tabular}{|c|c|c|c|c|}
\hline Characteristics & $\begin{array}{l}\text { Total }(n= \\
86)\end{array}$ & $\begin{array}{l}\text { Gamma } \\
(n=43)\end{array}$ & $\begin{array}{l}\text { non- } \\
\text { Gamma } \\
(n=43)\end{array}$ & $\begin{array}{l}P \\
\text { value }\end{array}$ \\
\hline Gender, male & $46(53.5)$ & $26(60.5)$ & $20(46.5)$ & 0.28 \\
\hline Age, years & $\begin{array}{l}51.0 \\
(43.5- \\
59.0)\end{array}$ & $\begin{array}{l}51.0 \\
(39.0- \\
58.0)\end{array}$ & $\begin{array}{l}51.0 \\
(46.0- \\
61.0)\end{array}$ & 0.39 \\
\hline Charlson's Comorbidity Score & $\begin{array}{l}1.0(0.0- \\
3.0)\end{array}$ & $\begin{array}{l}0.0(0.0- \\
2.0)\end{array}$ & $\begin{array}{l}2.0(0.0- \\
3.0)\end{array}$ & 0.04 \\
\hline \multicolumn{5}{|l|}{ Comorbidities } \\
\hline Diabetes & $22(25.6)$ & 9 (20.9) & $13(30.2)$ & 0.46 \\
\hline Hypertension & $47(54.7)$ & $20(46.5)$ & $27(62.8)$ & 0.19 \\
\hline Cardiovascular Disease & $15(17.4)$ & $5(11.6)$ & $10(23.3)$ & 0.26 \\
\hline Chronic Pulmonary Disease & $4(4.7)$ & $2(4.7)$ & $2(4.7)$ & 0.99 \\
\hline $\mathrm{BMI}, \mathrm{kg} / \mathrm{m}^{2} \mathrm{a}$ & $\begin{array}{l}31.0 \\
(27.3- \\
36.9)\end{array}$ & $\begin{array}{l}30.8 \\
(27.6- \\
36.9)\end{array}$ & $\begin{array}{l}31.2 \\
(28.0- \\
37.0)\end{array}$ & 0.65 \\
\hline $\mathrm{BMI} \geq 30 \mathrm{~kg} / \mathrm{m}^{2} \mathrm{a}$ & $51(63.8)$ & $26(63.4)$ & $25(64.1)$ & 0.99 \\
\hline $\begin{array}{l}\text { Time from onset of symptoms to hospital } \\
\text { admission, days }\end{array}$ & $\begin{array}{l}7.0(4.3- \\
9.0)\end{array}$ & $\begin{array}{l}7.0(4.0- \\
8.0)\end{array}$ & $\begin{array}{l}7.0(5.0- \\
9.0)\end{array}$ & 0.67 \\
\hline NEWS 2 & $\begin{array}{l}7.0(4.0- \\
9.0)\end{array}$ & $\begin{array}{l}7.0(5.5- \\
8.0)\end{array}$ & $\begin{array}{l}6.0(3.0- \\
9.0)\end{array}$ & 0.09 \\
\hline \multicolumn{5}{|l|}{$\mathrm{PaO} 2 / \mathrm{FiO} 2$ at admission } \\
\hline$>300$ & $39(45.3)$ & $16(37.2)$ & $23(53.5)$ & \multirow[t]{4}{*}{0.12} \\
\hline $300-201$ & $13(15.1)$ & $5(11.6)$ & $8(18.6)$ & \\
\hline $200-101$ & $16(18.6)$ & $9(20.9)$ & $7(16.3)$ & \\
\hline$\leq 100$ & $18(20.9)$ & $13(30.2)$ & $5(11.6)$ & \\
\hline \multicolumn{5}{|l|}{ Score on six-level ordinal scale } \\
\hline 2- hospitalization without supplemental oxygen & $30(34.9)$ & $11(25.6)$ & $19(44.2)$ & \multirow[t]{3}{*}{0.21} \\
\hline 3 - hospitalization with supplemental oxygen & $41(47.7)$ & $22(51.2)$ & $19(44.2)$ & \\
\hline $\begin{array}{l}4 \text { - hospitalization with non-invasive ventilation or } \\
\text { high-flow supplemental oxygen }\end{array}$ & $8(9.3)$ & $6(14.0)$ & $2(4.7)$ & \\
\hline
\end{tabular}




\begin{tabular}{|c|c|c|c|c|}
\hline Characteristics & $\begin{array}{l}\text { Total }(n= \\
86)\end{array}$ & $\begin{array}{l}\text { Gamma } \\
(n=43)\end{array}$ & $\begin{array}{l}\text { non- } \\
\text { Gamma } \\
(\mathrm{n}=43)\end{array}$ & $\begin{array}{l}\mathrm{P} \\
\text { value }\end{array}$ \\
\hline $\begin{array}{l}5 \text { - hospitalization with invasive mechanical } \\
\text { ventilation and/or extracorporeal membrane } \\
\text { oxygenation }\end{array}$ & $7(8.1)$ & $4(9.3)$ & $3(7.0)$ & \\
\hline \multicolumn{5}{|l|}{ Oxygen delivery device } \\
\hline None & $30(34.9)$ & $11(25.6)$ & $19(44.2)$ & \multirow[t]{6}{*}{0.48} \\
\hline Low-flow nasal cannula & $19(22.1)$ & $10(23.3)$ & $9(20.9)$ & \\
\hline Hudson mask & $22(25.6)$ & $12(27.9)$ & $10(23.3)$ & \\
\hline Non-invasive ventilator & $4(4.7)$ & $3(7.0)$ & $1(2.3)$ & \\
\hline High flow nasal cannula & $4(4.7)$ & $3(7.0)$ & $1(2.3)$ & \\
\hline Invasive mechanical ventilator & $7(8.1)$ & $4(9.3)$ & $3(7.0)$ & \\
\hline \multicolumn{5}{|l|}{ Laboratorial findings } \\
\hline Ct, N1 & $\begin{array}{l}20.35 \pm \\
3.24\end{array}$ & $\begin{array}{l}19.74 \pm \\
3.35\end{array}$ & $\begin{array}{l}20.96 \pm \\
3.05\end{array}$ & 0.08 \\
\hline Ct, N2 & $\begin{array}{l}20.58 \pm \\
3.42\end{array}$ & $\begin{array}{l}20.30 \pm \\
3.73\end{array}$ & $\begin{array}{l}20.86 \pm \\
3.09\end{array}$ & 0.45 \\
\hline White blood cell count, cells $\times 10^{3} / \mu \mathrm{L}^{\mathrm{b}}$ & $\begin{array}{l}7.2(5.4- \\
10.6)\end{array}$ & $\begin{array}{l}7.0(5.2- \\
10.6)\end{array}$ & $\begin{array}{l}8.0(5.5- \\
10.9)\end{array}$ & 0.72 \\
\hline Neutrophil count, cells $\times 10^{3} / \mu \mathrm{L}^{\mathrm{b}}$ & $\begin{array}{l}5.7(4.1- \\
8.5)\end{array}$ & $\begin{array}{l}5.6(4.0- \\
9.3)\end{array}$ & $\begin{array}{l}6.2(4.2- \\
8.5)\end{array}$ & 0.71 \\
\hline Lymphocyte count, cells/ $\mu \mathrm{L}^{\mathrm{b}}$ & $\begin{array}{l}826.1 \\
(637.6- \\
1211.8)\end{array}$ & $\begin{array}{l}770.0 \\
(563.7- \\
1004.0)\end{array}$ & $\begin{array}{l}870.4 \\
(676.5- \\
1239.8)\end{array}$ & 0.13 \\
\hline Platelet count, cells $\times 10^{3} / \mu \mathrm{L}^{b}$ & $\begin{array}{l}205.5 \\
(155.0- \\
265.0)\end{array}$ & $\begin{array}{l}181.0 \\
(142.0- \\
226.0)\end{array}$ & $\begin{array}{l}246.0 \\
(174.0- \\
279.5)\end{array}$ & 0.01 \\
\hline$C$ reactive protein, $\mathrm{mg} / \mathrm{L}^{\mathrm{c}}$ & $\begin{array}{l}124.5 \\
(75.6- \\
202.0)\end{array}$ & $\begin{array}{l}123.6 \\
(74.2- \\
191.1)\end{array}$ & $\begin{array}{l}126.8 \\
(83.1- \\
205.0)\end{array}$ & 0.62 \\
\hline D-dimer, $\mu \mathrm{g} / \mathrm{mL}^{\mathrm{d}}$ & $\begin{array}{l}0.8(0.5- \\
1.4)\end{array}$ & $\begin{array}{l}0.8(0.5- \\
1.4)\end{array}$ & $\begin{array}{l}0.9(0.4- \\
1.4)\end{array}$ & 0.99 \\
\hline Serum creatinine, $\mathrm{mg} / \mathrm{dL}^{\mathrm{e}}$ & $\begin{array}{l}0.9(0.8- \\
1.4)\end{array}$ & $\begin{array}{l}0.9(0.8- \\
1.4)\end{array}$ & $\begin{array}{l}1.0(0.8- \\
1.3)\end{array}$ & 0.78 \\
\hline \multicolumn{5}{|c|}{$\begin{array}{l}\text { Data expressed as } n(\%) \text {, median (IQR) or mean } \pm \text { SD. BMI, body mass index; PaO2/FiO2, partial } \\
\text { pressure of arterial oxygen / fractional inspired oxygen; NEWS, National Early Warning Score; Ct, cycle } \\
\text { threshold. }\end{array}$} \\
\hline
\end{tabular}




\section{Characteristics}

Total $(\mathrm{n}=$

86)
Gamma

$(n=43)$ non-

Gamma

$(n=43)$

a Two (4.7\%) patients in P.1 and 4 (9.3\%) in non-P.1.did not have BMI recorded.

b One (1.2\%) patient from P.1 group did not have white blood cells recorded; and one (2.3\%) patient in P.1 did not have platelets recorded.

${ }^{\mathrm{c}}$ Two (4.7\%) in P.1 and 3 (7.0\%) in non-P.1 did not have $\mathrm{C}$ reactive protein recorded.

d One (1.2\%) patient from P.1 group did not have D-dimers recorded.

2 Three (7.0\%) patients from non-P.1 did not have creatinine recorded.

\section{Outcomes}

A total of 72 (83.7\%) patients required advanced respiratory support (non-invasive ventilation [36, 50.0\%], high-flow nasal cannula [23,31.9\%] or mechanical ventilation [13, 18.1\%]): 40 (93.0\%) in Gamma and 32 $(74.4 \%)$ in non-Gamma patients (Relative Risk [RR], 1.25; 95\% Confidence Interval [Cl], 1.03-1.52; P = 0.04). The median time from onset of symptoms to advanced respiratory support was 9 days (IQR, 7$11): 8.5$ days $(7-11)$ in Gamma and $9(8-10)$ in non-Gamma patients $(P=0.06)$. The incidence rate of advanced respiratory support was significantly higher in Gamma than in non-Gamma patients, $P=0.05$ (Fig. 2).

Twenty-nine (67.4\%) and 14 (32.6\%) Gamma and non-Gamma patients, respectively, required invasive respiratory support (RR, 1.93; 95\% $\mathrm{Cl}, 1.22-3.09 ; \mathrm{P}=0.005)$. Eleven (25.6\%) Gamma and $3(7.0 \%)$ nonGamma patients died in the first 28 days from the onset of symptoms (RR, 3.67; 95\% Cl, 1.10-12.23; $\mathrm{P}=$ 0.04). After hospitalization, 28-day mortality was $25.6 \%$ (11 patients) and $11.6 \%$ (5 patients) in Gamma and non-Gamma groups, respectively $(\mathrm{RR}, 2.20 ; 95 \% \mathrm{Cl}, 0.84-5.80 ; \mathrm{P}=0.17)$. The incidence rate of invasive respiratory support $(P=0.03)$ and death from onset of symptoms $(P=0.04)$ were significantly higher in Gamma than in non-Gamma patients (Fig. 2); while the unadjusted incidence rate of death after hospitalization was non-significantly higher $(P=0.10)$ in Gamma than in non-Gamma patients (Fig. 2).

The risk of being dead or under invasive ventilation was significantly higher for Gamma than nonGamma infected patients on days 7, 14, 21 and 28 (Additional file 1: STable 3); and the risk of having severe acute respiratory distress syndrome was significantly higher in Gamma patients on days 7 and 14 from hospitalization (Additional file 1: STable 4). The distribution of patients in the ordinal scale in the first 28 days from hospitalization and the progression of PaO2/FiO2 in Gamma and non-Gamma groups are shown in Fig. 3.

Patients infected by Gamma had significantly lower days alive and free of supplemental oxygen support than those infected by non-Gamma lineages (median, 2.0 days; IQR, 0.0-15.5 versus 18.0 days; IQR, 2.5$22.5 ; \mathrm{P}<0.001)$. There were no statistically significant differences between Gamma and non-Gamma 
patients in admission to ICU, need of renal replacement therapy, prone positioning, occurrence of thromboembolic event and in-hospital mortality (Additional file 1: STable 5). There was no significant difference in leukocyte counts, lymphocyte counts, $\mathrm{C}$ reactive protein and creatinine between groups along hospitalization (Additional file 1:SFigure 1).

In the Cox proportional hazard model, Gamma infection was associated with a higher risk of requiring advanced respiratory support (Table 2). The incidence rate of mechanical ventilation, death after 28 days from onset of symptoms and from hospital admission were also significantly higher in Gamma than in non-Gamma-infected patients after adjustment for covariates (Table 2). 
Table 2

Multivariate models for the advanced respiratory support, invasive ventilatory support, and 28-day mortality from the onset of symptoms and from hospitalization.

Variable
$\begin{aligned} & \text { Model 1: Advanced respiratory support from onset of } \\ & \text { symptoms }\end{aligned}{ }^{\text {a }}$

Hazard ratio
95\% Confidence Interval $\mathbf{P}$

\begin{tabular}{|lccc|}
\hline Gamma infection & 1.78 & $1.05-3.03$ & 0.03 \\
\hline Age & 1.01 & $0.99-1.03$ & 0.56 \\
\hline Sex, male & 1.24 & $0.76-2.03$ & 0.40 \\
\hline Charlson's Score & 1.00 & $0.91-1.10$ & 0.93 \\
\hline Body Mass Index & 1.04 & $1.02-1.07$ & 0.02
\end{tabular}

Model 2: Invasive respiratory support from onset of symptoms $^{\text {b }}$
Gamma infection
2.64
$1.34-5.19$
0.005
Age
1.02
0.99-1.05
0.17
Sex, male
1.17
$0,62-2.21$
0.62
Charlson's Score
1.04
$0.93-1.16$
0.53
Body Mass Index
1.01
0.97-1.04
0.64

Model 3: 28-day mortality from onset of symptoms

\begin{tabular}{llll} 
Gamma infection & 4.73 & $1.15-19.41$ & 0.03 \\
\hline Age & 1.04 & $0.98-1.10$ & 0.18 \\
Sex, male & 1.13 & $0.35-3.61$ & 0.84 \\
Charlson's Score & 1.14 & $0.94-1.39$ & 0.20 \\
\hline Body Mass Index & 0.97 & $0.88-1.06$ & 0.45
\end{tabular}

Model 4: 28-day mortality from hospital admission ${ }^{c}$

Gamma infection

3.72

$1.19-11.65$

0.02

a Advanced respiratory support was considered non-invasive ventilation, high-flow oxygen support, mechanical ventilation or extracorporeal membrane oxygenation.

${ }^{b}$ Invasive respiratory support was considered mechanical ventilation or extracorporeal membrane oxygenation.

${ }^{c}$ Forcing age into the model did not modify the effect of Gamma lineage on the outcome. 


\begin{tabular}{|lclc|}
\hline Variable & $\begin{array}{l}\text { Hazard } \\
\text { ratio }\end{array}$ & $\begin{array}{l}\text { 95\% Confidence } \\
\text { Interval }\end{array}$ & $\mathbf{P}$ \\
\hline Age & 1.02 & $0.97-1.07$ & 0.45 \\
\hline Charlson`s Score & 1.21 & $1.05-1.38$ & 0.007 \\
\hline $\begin{array}{l}\text { a Advanced respiratory support was considered non-invasive ventilation, high-flow oxygen support, } \\
\text { mechanical ventilation or extracorporeal membrane oxygenation. }\end{array}$ & \\
\hline $\begin{array}{l}\text { b Invasive respiratory support was considered mechanical ventilation or extracorporeal membrane } \\
\text { oxygenation. }\end{array}$ & \multicolumn{4}{|l}{} \\
\hline c Forcing age into the model did not modify the effect of Gamma lineage on the outcome.
\end{tabular}

\section{Sensitivity analysis}

Patients from the second period (presumably Gamma) had significantly lower comorbidity score than patients from the first period (presumably non-Gamma) in the sensitivity cohort. Gamma patients also had significantly more severe acute respiratory distress syndrome and less frequently presented PaO2/FiO2 above 300 at admission (Additional file 1: STable 6); and had more often scores 4 or 5 in the ordinal clinical scale and less often score 2 than non-Gamma patients at admission (Additional file 1: STable 6).

The unadjusted risk for advanced and invasive respiratory support, 28-day mortality from onset of symptoms and from hospital admission were significantly higher in patients from the second than the first period (Fig. 4 and Additional file 1: STable 7). The adjusted risks for advanced respiratory support (P $<0.001)$, invasive ventilatory support $(P<0.001)$, and 28-day mortality from the onset of symptoms $(P=$ 0.001 ) were significantly higher in patients from the second than the first period (Additional file 1: STable 7). The risk for 28-day mortality from hospital admission $P=0.09$ ) was not statistically significant after adjustment (Supplemental Digital Table 8).

\section{Discussion}

The collective findings of this retrospective cohort with non-elderly adult patients attending at the emergency department of a COVID-19 reference hospital suggest that infections caused by the Gamma VOC present a more severe course of disease, indicated by higher incidence rates of advanced and invasive respiratory support, death in the first 28 days from the onset of symptoms compared to patients with infections by other lineages, mostly B.1.1.28 and B.1.1.161, which are not VOCs.

The results were similar in the sensitivity cohort indicate that the sequenced sample is representative of the eligible population. Furthermore, the sensitivity cohort corroborates the hypothesis that Gamma infections are associated with an unfavorable course of COVID-19, since patients from the second period presented at emergency department in worse clinical status, despite the remarkably similar time from 
onset of symptoms to admission in both groups, as evidenced by higher scores in ordinal clinical scale and lower $\mathrm{PaO} 2 / \mathrm{FiO} 2$ ratios.

Differently from previous studies with Alpha versus non-VOC $[5-9,12]$, and with Delta compared to Alpha [18], which mainly analyzed the risk of hospitalization or in-hospital death, our study provided more detail in the ventilatory demand along the clinical course of COVID-19 caused by the Gamma VOC and other SARS-CoV-2 lineages. Advanced respiratory support was chosen as the primary outcome because during the Gamma surge, there was a restriction in the number of ICU beds available $[14,16]$; thus, we a priori considered that differences in the incidence of mechanical ventilation, for example, could not be detected since invasive ventilatory support might be postponed due to limited access to ICU during this period. For instance, Bastos et al.[16] have shown that the second wave in Brazil was associated with higher mortality among hospitalized patients but not with higher ICU admission, which might suggest a potential limitation in access to critical care. Surprisingly, the incidence rate of invasive respiratory support from the onset of symptoms was significantly higher in patients infected by Gamma, even in the context of restricted access to ICU, corroborating to the hypothesis that infections by Gamma resulted in more severe disease.

We included only non-elderly patients to minimize the effect of age on the course of the disease. Along with adjustment for age in the multivariable model, this was important to minimize the effect of this extremely relevant confounding factor. Additionally, despite the effect of aging oh the course of COVID19 , including higher age groups VOC will introduce vaccination as another confounding factors. The vaccination of individuals who were 65 years started on early April in our State. Since we could not have these data standardly registered in medical records, it is possible that some patients of our study have received the first shot when admitted. However, vaccinated patients in Gamma or second period groups favor the null hypothesis, since it is a factor of protection for more severe disease.

In addition to those inherent to the retrospective design, our study has some limitations that must be acknowledged. First, it must be considered that it is a single center experience of a large tertiary-care COVID-19 reference hospital, which may restrict generalizability. Second, since Gamma and non-Gammainfected patients were hospitalized in different periods, they might be affected by distinct practices in COVID-19 management. However, it should be noted that more than $90 \%$ of patients have been treated with corticosteroids and there was no other pharmacological intervention used in the second period. Furthermore, if better practices in COVID-19 patients care had been incorporated in more recent periods, it would favor the null hypothesis. Third, the magnitude of the effect of Gamma on 28-day mortality in the main cohort must be interpreted with caution because of the low number of this events, which resulted in a large $95 \% \mathrm{Cl}$ in the model. The lower adjusted risk in the sensitivity cohort more likely reflects the magnitude of the effect of Gamma infections. Fourth, the study might be affected by a selection bias because the higher hospital occupancy in the second period may have delayed the admission of less severe cases. Nonetheless, it must be pointed out that time from onset of symptoms to hospital admission were essentially the same in both main and sensitivity cohorts. Finally, our study addressed 
clinical evolution of patients with severe COVID-19 that required hospital admission and the finding cannot be extrapolated to outpatient population.

\section{Conclusions}

Our study suggests that in non-elderly adult patients who require hospital admission, COVID-19 caused by Gamma present a more severe clinical course, as evidenced by the higher incidence of advanced respiratory support and 28-day mortality in patients infected by the Gamma VOC. In addition to the elevated number of cases resulting in ICU overload, increased severity of COVID-19 caused by Gamma lineage may have contributed to the remarkably high ICU occupancy and death observed in the surge of this VOC.

\section{Declarations}

\section{Authors' contributions}

APZ and ALB conceptualized the study. PLW, FCZV, FLM and JBW performed the NGS experiments. AFM performed bioinformatic analysis and data interpretation. Data collection was performed by TV, BA, GOMC and MSN. CFF led the statistical analyses, which were checked by APZ. All authors contributed to the interpretation of the results. AZP, TV, PLW and ALB wrote the first draft of the paper. All authors contributed to the critical revision of the manuscript for important intellectual content and approved the final version of the manuscript.

\section{Funding}

This study was funded by "Fundação de Amparo à Pesquisa do Estado do Rio Grande do Sul FAPERGS" (Project numbers 20/2551-0000265-9 and 16/2551-0000242-8).

\section{Availability of data and materials}

The datasets analyzed during the current study are available from the corresponding author on reasonable request.

\section{Declarations}

\section{Ethics approval and consent to participate}

This study is part of a research project on the epidemiology of SARS-CoV-2. It has been approved by the Institutional Ethics Committee (Project no. 2020-0163), which waived informed consent. A specific amendment to this study was submitted and approved by this committee.

\section{Consent for publication}

Not applicable. 


\section{Competing interests}

APZ received a research grant from Pfizer not related to this work. All other authors declare no competing interests. APZ, ALB and AFM are research fellows of the National Council for Scientific and Technological Development (CNPq), Ministry of Science and Technology, Brazil.

\section{Abbreviations}

Cl: Confidence Interval; COVID-19: Coronavirus Disease 19; Ct: Cycle threshold; Intensive Care Unit: ICU; HCPA: Hospital de Clínicas de Porto Alegre; HR: Hazard Ratio; PaO2/FiO2: Partial pressure of arterial oxygen/ Fraction of inspired oxygen; RT-qPCR: Real-time Reverse Transcriptase Polymerase Chain Reaction; RR: Relative Risk; SARS-CoV-2= Severe Acute Respiratory Syndrome Coronavirus 2; VOC: Variant of Concern; WGS: Whole Genome Sequencing.

\section{References}

1. Campbell F, Archer B, Laurenson-Schafer H, Jinnai Y, Konings F, Batra N, Pavlin B, Vandemaele K, Van Kerkhove MD, Jombart T, et al: Increased transmissibility and global spread of SARS-CoV-2 variants of concern as at June 2021. Euro Surveill 2021, 26(24).

2. Davies NG, Abbott S, Barnard RC, Jarvis Cl, Kucharski AJ, Munday JD, Pearson CAB, Russell TW, Tully DC, Washburne AD, et al: Estimated transmissibility and impact of SARS-CoV-2 lineage B.1.1.7 in England. Science 2021, 372(6538).

3. Faria NR, Mellan TA, Whittaker C, Claro IM, Candido DDS, Mishra S, Crispim MAE, Sales FCS, Hawryluk I, McCrone JT, et al. Genomics and epidemiology of the P.1 SARS-CoV-2 lineage in Manaus, Brazil. Science. 2021;372(6544):815-21.

4. Khateeb J, Li Y, Zhang H. Emerging SARS-CoV-2 variants of concern and potential intervention approaches. Crit Care. 2021;25(1):244.

5. Nyberg T, Twohig KA, Harris RJ, Seaman SR, Flannagan J, Allen H, Charlett A, De Angelis D, Dabrera G, Presanis AM. Risk of hospital admission for patients with SARS-CoV-2 variant B.1.1.7: cohort analysis. Bmj. 2021;373:n1412.

6. Bager P, Wohlfahrt J, Fonager J, Rasmussen M, Albertsen M, Michaelsen TY, Møller CH, Ethelberg S, Legarth R, Button MSF, et al: Risk of hospitalisation associated with infection with SARS-CoV-2 lineage B.1.1.7 in Denmark: an observational cohort study. Lancet Infect Dis 2021.

7. Davies NG, Jarvis Cl, Edmunds WJ, Jewell NP, Diaz-Ordaz K, Keogh RH. Increased mortality in community-tested cases of SARS-CoV-2 lineage B.1.1.7. Nature. 2021;593(7858):270-4.

8. Grint DJ, Wing K, Williamson E, McDonald HI, Bhaskaran K, Evans D, Evans SJ, Walker AJ, Hickman G, Nightingale E, et al: Case fatality risk of the SARS-CoV-2 variant of concern B.1.1.7 in England, 16 November to 5 February. Euro Surveill 2021, 26(11). 
9. Challen R, Brooks-Pollock E, Read JM, Dyson L, Tsaneva-Atanasova K, Danon L. Risk of mortality in patients infected with SARS-CoV-2 variant of concern 202012/1: matched cohort study. Bmj. 2021;372:n579.

10. Ong SWX, Young BE, Lye DC. Lack of detail in population-level data impedes analysis of SARS-CoV-2 variants of concern and clinical outcomes. Lancet Infect Dis 2021.

11. Frampton D, Rampling T, Cross A, Bailey H, Heaney J, Byott M, Scott R, Sconza R, Price J, Margaritis $M$, et al: Genomic characteristics and clinical effect of the emergent SARS-CoV-2 B.1.1.7 lineage in London, UK: a whole-genome sequencing and hospital-based cohort study. Lancet Infect Dis 2021.

12. Patone M, Thomas K, Hatch R, Tan PS, Coupland C, Liao W, Mouncey P, Harrison D, Rowan K, Horby P, et al: Mortality and critical care unit admission associated with the SARS-CoV-2 lineage B.1.1.7 in England: an observational cohort study. Lancet Infect Dis 2021.

13. Naveca FG, Nascimento V, de Souza VC, Corado AL, Nascimento F, Silva G, Costa Á, Duarte D, Pessoa $\mathrm{K}$, Mejía M, et al: COVID-19 in Amazonas, Brazil, was driven by the persistence of endemic lineages and P.1 emergence. Nat Med 2021.

14. Martins AF, Zavascki AP, Wink PL, Volpato FCZ, Monteiro FL, Rosset C, De-Paris F, Ramos ÁK, Barth AL. Detection of SARS-CoV-2 lineage P.1 in patients from a region with exponentially increasing hospitalisation rate, February 2021, Rio Grande do Sul, Southern Brazil. Euro Surveill 2021, 26(12).

15. Paul P, France AM, Aoki Y, Batra D, Biggerstaff M, Dugan V, Galloway S, Hall AJ, Johansson MA, Kondor RJ, et al. Genomic Surveillance for SARS-CoV-2 Variants Circulating in the United States, December 2020-May 2021. MMWR Morb Mortal Wkly Rep. 2021;70(23):846-50.

16. Bastos LS, Ranzani OT, Souza TML, Hamacher S, Bozza FA. COVID-19 hospital admissions: Brazil's first and second waves compared. Lancet Respir Med 2021.

17. Funk T, Pharris A, Spiteri G, Bundle N, Melidou A, Carr M, Gonzalez G, Garcia-Leon A, Crispie F, O'Connor $L$, et al: Characteristics of SARS-CoV-2 variants of concern B.1.1.7, B.1.351 or P.1: data from seven EU/EEA countries, weeks 38/2020 to 10/2021. Euro Surveill 2021, 26(16).

18. Twohig KA, Nyberg T, Zaidi A, Thelwall S, Sinnathamby MA, Aliabadi S, Seaman SR, Harris RJ, Hope $\mathrm{R}$, Lopez-Bernal J, et al: Hospital admission and emergency care attendance risk for SARS-CoV-2 delta (B.1.617.2) compared with alpha (B.1.1.7) variants of concern: a cohort study. The Lancet Infectious Diseases.

\section{Figures}


2434 patients had a positive SARS-CoV-2 molecular tests collected at the emergency department

954 aged $<18$ or $>65$ years excluded

1462 patients aged 18 to 65 years

536 asymptomatic patients who collected

RT-qPCR for screening purposes excluded

926 symptomatic patients aged 18 to 65 years

511 excluded:

261 had a $\mathrm{Ct} \geq 26.0$

71 had been transferred from other institutions

179 collected non RT-qPCR

molecular tests

433 patients eligible for study inclusion

(Sensitivity Cohort):

259 from the first period

174 from the second period

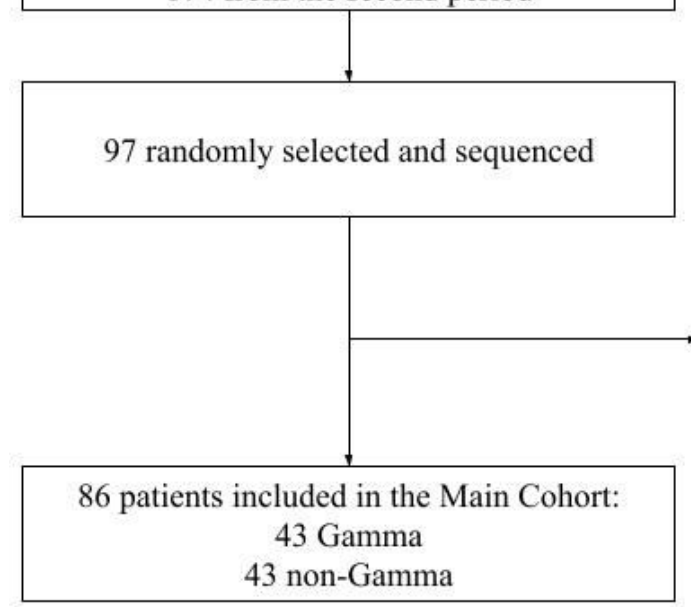

11 excluded:

8 low quality sequencing

3 ( 1 Gamma and 2 non-Gamma)

after sample size reached

\section{Figure 1}

Study flowchart. Sensitivity cohort: First period: 1st June to 31st December/2020 (before the first detection of Gamma in Rio Grande do Sul State, where the study was conducted); and Second period: 1st February to 31st May/2021 (after the first detection of Gamma in late January/2021). 
Advanced respiratory support

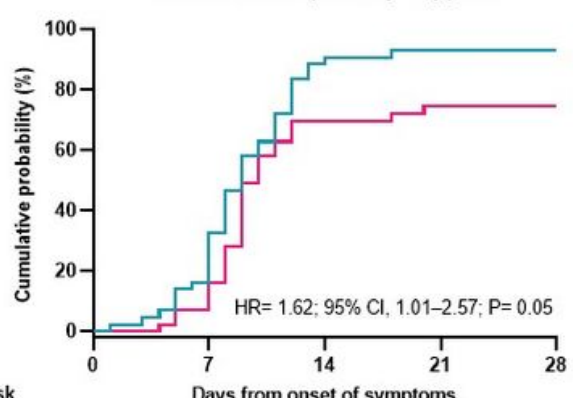

Number at risk

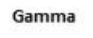

Non-Gamma

Days from onset of symptoms

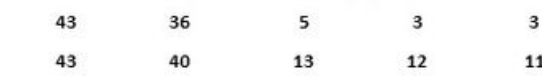

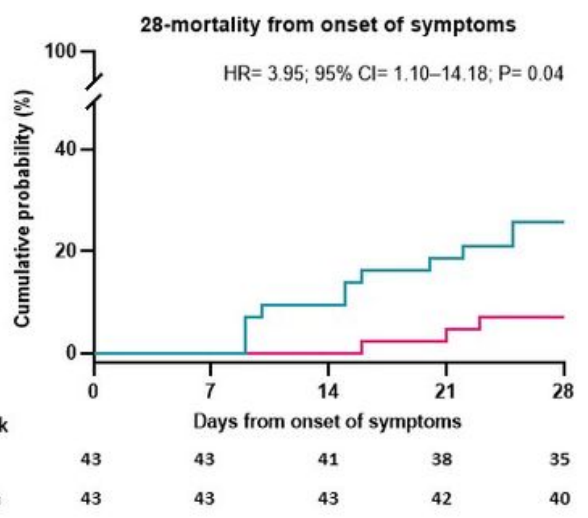

Invasive respiratory support
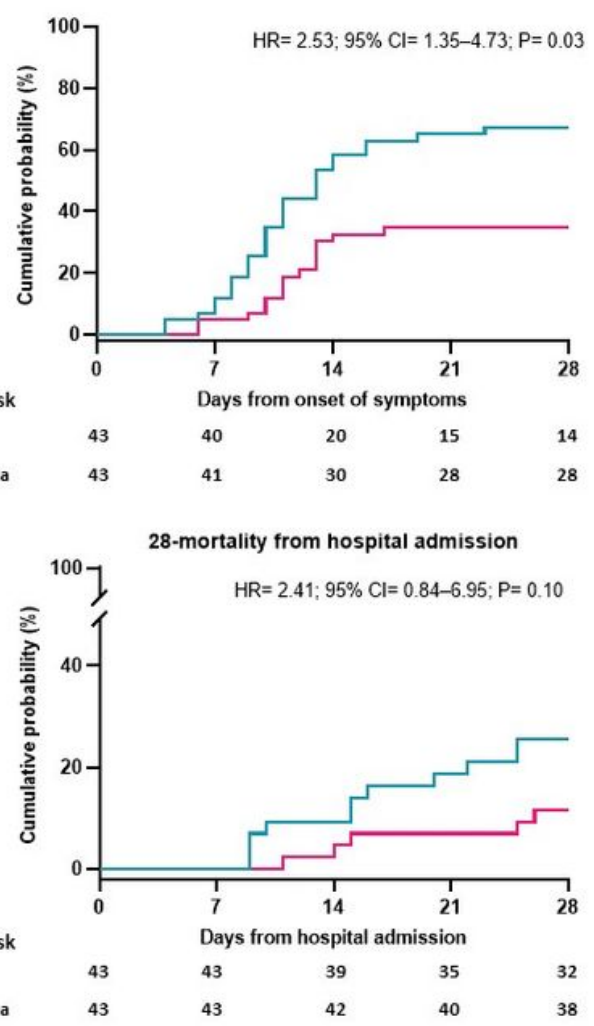

\section{Figure 2}

Primary and major secondary outcomes in the main cohort. HR, Hazard Ratio; $\mathrm{Cl}$, Confidence Interval. 


\section{A. Six-level ordinal scale distribution}

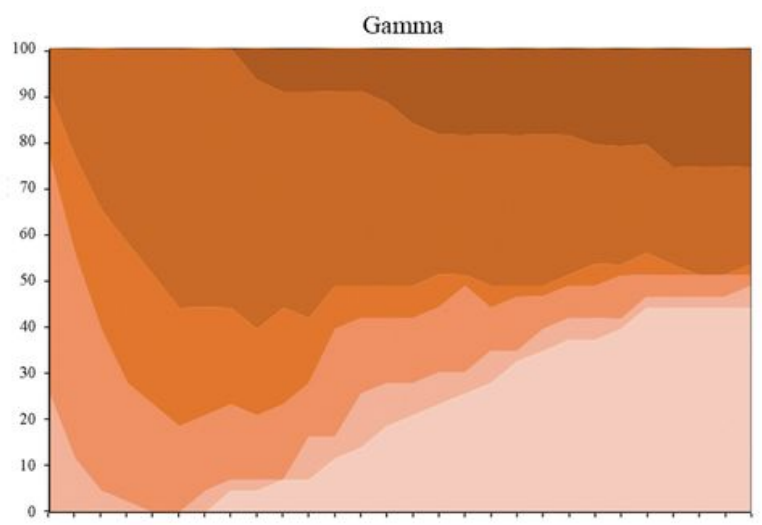

non-Gamma

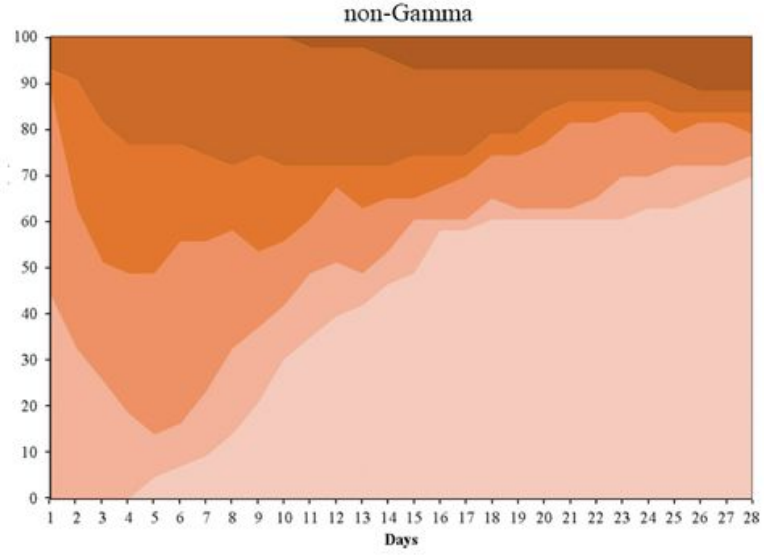

B. $\mathrm{PaO}_{2} / \mathrm{FiO}_{2}$ distribution
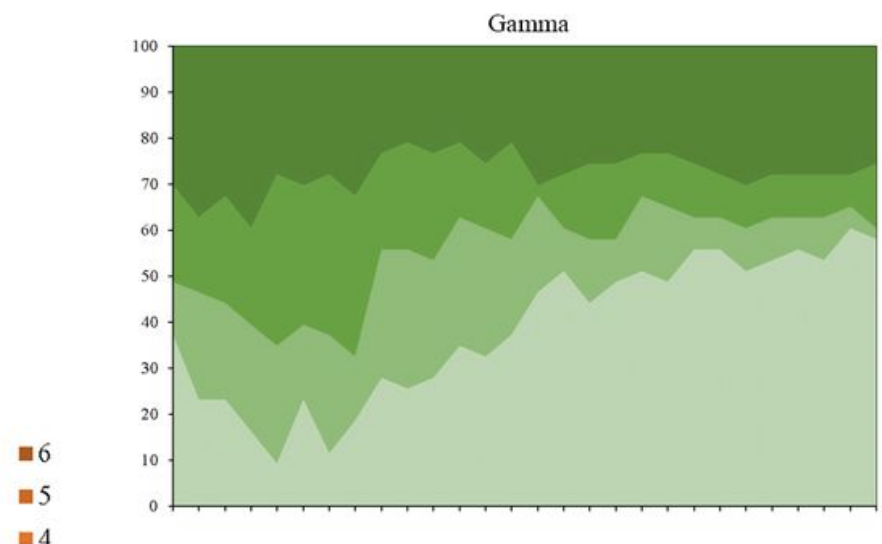

non-Gamma

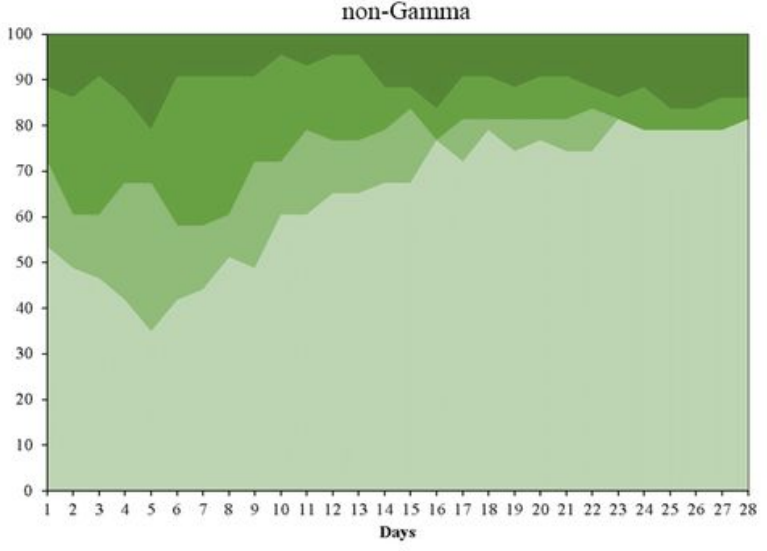

미 $\leq 100$

모 $101-200$

무 $201-300$

믹 $>300$

\section{Figure 3}

Ordinal clinical scale (A) and pressure arterial oxygen/ fraction of inspired oxygen ratio (PaO2/FiO2) (B) in the first 28 days from hospitalization. Ordinal clinical scale: 1, patient not hospitalized; 2 , hospitalized and not receiving supplemental oxygen; 3 , hospitalized and receiving supplemental oxygen; 4 , hospitalized and receiving oxygen supplementation administered by non-invasive ventilation or high flow nasal cannula; 5 , hospitalized and receiving mechanical ventilation or extra-corporeal membrane oxygenation; and 6, death (Additional file 1: STable 3 and STable 4) 
Advanced respiratory support

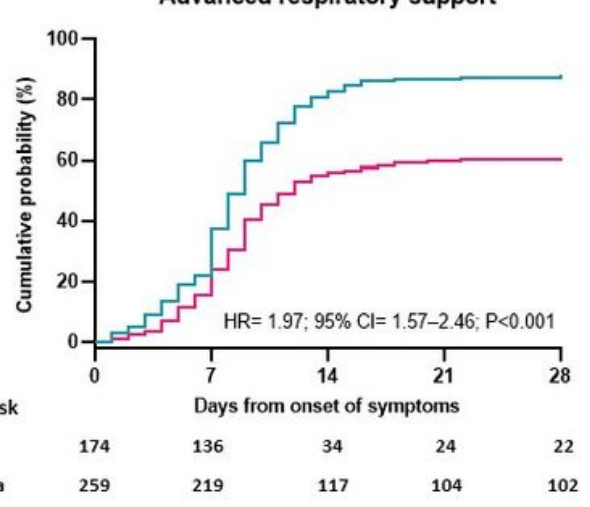

Number at risk

Gamma

Non-Gamm
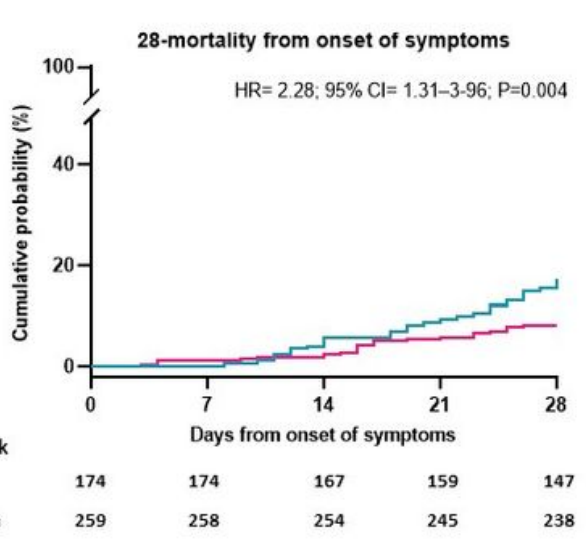

Number at risk

Gamma

Non-Gamma

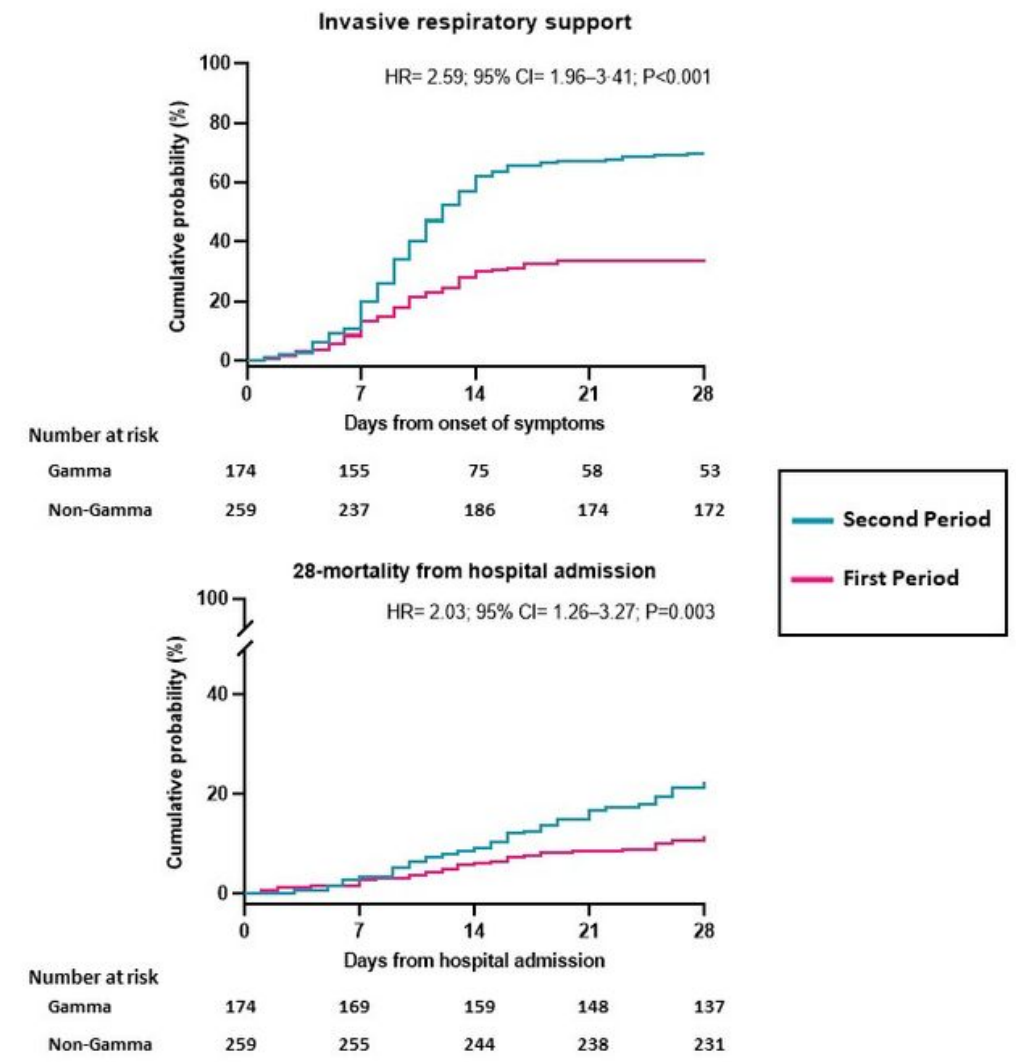

Figure 4

Primary and major secondary outcomes in the sensitivity cohort. HR, Hazard Ratio; Cl, Confidence Interval. The second period group includes 174 eligible patients from with presumably Gamma infections. The first period group includes 259 eligible patients with presumably non-Gamma infections.

\section{Supplementary Files}

This is a list of supplementary files associated with this preprint. Click to download.

- GammaCCGraphAbstract.jpg

- GammaCCSupplement.pdf 